\title{
Experimental modification of rat pituitary prolactin cell function during and after spaceflight
}

\author{
W. C. HYMER, T. SALADA, L. AVERY, AND R. E. GRINDELAND \\ Department of Biochemistry and Molecular Biology, The Pennsylvania State University, \\ University Park, Pennsylvania 16802; and National Aeronautics and Space Administration \\ Ames Research Center, Moffett Field, California 94035
}

\begin{abstract}
Hymer, W. C., T. Salada, L. Avery, and R. E. Grindeland. Experimental modification of rat pituitary prolactin cell function during and after spaceflight. J. Appl. Physiol. 80(3): 971-980, 1996. - This study was done to evaluate the effects of microgravity on prolactin (PRL) cells of the male rat pituitary gland. We used the identical passive closed-vial cell culture system that was described for the culture of growth hormone cells (W. C. Hymer, R. E. Grindeland, T. Salada, P. Nye, E. Grossman, and P. Lane. J. Appl. Physiol. 80: 955-970, 1996). After an 8-day spaceflight, all flight media (containing released PRL), as well as extracts (containing intracellular PRL), contained significantly lower amounts of immunoreactive PRL than their corresponding ground control samples. On the other hand, these same samples, when assessed for their biological activities by two different in vitro lymphocyte assays, yielded disparate results that may reflect posttranslational modifications to the hormone molecule. Other data showed that 1) the apparent molecular weights of released PRL molecules were not altered by microgravity, but 2 ) the region from which the PRL cells came (dorsal or ventral) made a significant difference in the amount and activity of PRL released from the flight cells. Because there is much current interest in the role that PRL may play in the regulation of the immune system and because changes in both cellular and humoral immunity accompany spaceflight, this study could help define future microgravity research in this area.

microgravity; cell culture
\end{abstract}

PROLACTIN (PRL), a pituitary hormone that bears a structural similarity to growth hormone (GH), is well known for its diversity of physiological actions (17). Although originally thought to function exclusively as a reproductive hormone, there is now convincing evidence for its additional role in the modulation of the mammalian immune system (2). Like GH, numerous PRL variants exist within the pituitary as a result of posttranslational modifications (20); when released from their cells of origin into the circulation, the biological activities of these variants may escape detection by conventional immunoassays (10). Fortunately, two sensitive in vitro bioassays for PRL are now available to test for biological activities of secreted PRL. One of these, the NB-2 cell bioassay, is based on the ability of the hormone to increase cell division in a line of T-lymphoma cells (22). The other, the interleukin-2 receptor-mitogen assay, uses fresh splenocytes from the ovariectomized female rat to test the ability of the hormone to either cause induction of interleukin-2 cell surface receptors or division in these primary cells $(14,24)$.
The morphology of the PRL cell in the pituitary gland of the male rat after spaceflight was recently characterized by Thapar et al. (23). These authors reported that there were neither qualitative nor quantitative morphological differences in this cell population between control and spaceflown animals. We also reported that PRL cells of spaceflown rats had similar morphologies to their ground-based counterparts (7). However, we also obtained preliminary evidence that PRL cell function might be affected by spacefiight.

The design of the 1992 pituitary cell culture experiment in microgravity allowed us to further investigate PRL cell structure and function under in vitro conditions in addition to the study of the structure and function of $\mathrm{GH}$ cells that is described in the companion report (8). This report documents that changes in intracellular and released PRL occur in cells during and after spaceflight.

\section{MATERIALS AND METHODS}

Details relating to 1 ) experimental design, 2) cell culture methods, 3) cell morphology methods (5), 4) high-performance liquid chromatography (HPLC) methods, and 5) data presentation are described in the companion report (8).

\section{Hormone Assays}

The PRL enzyme immunoassay was done exactly as described previously (19) with polyclonal antiserum (crossreactivity to $\mathrm{GH}$ is $<0.3 \%$ at a dilution of $1: 40,000$ ). Each sample was analyzed in duplicate at two dilutions, and the results are expressed relative to a rat PRL standard (B-7) kindly provided by the National Institute of Diabetes and Digestive and Kidney Diseases (Bethesda, MD) and the National Hormone and Pituitary Program (University of Maryland School of Medicine, Baltimore, MD).

PRL bioassays were either 1 ) the NB-2 lymphoma cell division assay originally described by Tanaka et al. (22) or 2) the mitogen assay described by Viselli et al. (24).

Experimental constraints within this spaceflight investigation resulted in low $n$ sizes. Accordingly, multiple $\alpha$-levelcorrected independent $t$-tests were used to analyze these data. This, in turn, permitted the use of an inferential technique to highlight differences as well as strong trends. Significance was maintained at $P \leq 0.05$.

\section{RESULTS}

\section{PRL Cell Morphology}

The viability of all cells before and after flight was $>90 \%$. The percentages of PRL cells in the samples at the time of seeding, based on flow cytometry, were 1) $30 \%$ for mixed cells, 2) $38 \%$ for band 1 cells, and 3) $21 \%$ for band 2 cells. After flight, these percentages, based 
Fig. 1. Flow cytometric histograms of pituitary cells contained in mixed $(A)$, band 1 $(B)$, and band $2(C)$ samples before seeding into glass vials. Log peak green fluorescence (LPGFL) staining is specific for prolactin (PRL) cells and delineates stained [identified as cells falling to right of vertical gate (vertical line)] from unstained cells that include other hormone-producing cell types gated from debris on basis of propidium iodide nuclear stain. LPGFL is on a log scale, whereas forward-angle light scatter (FALS), a measure of cell size, is linear. Each pattern represents a count of 30,000 cells.
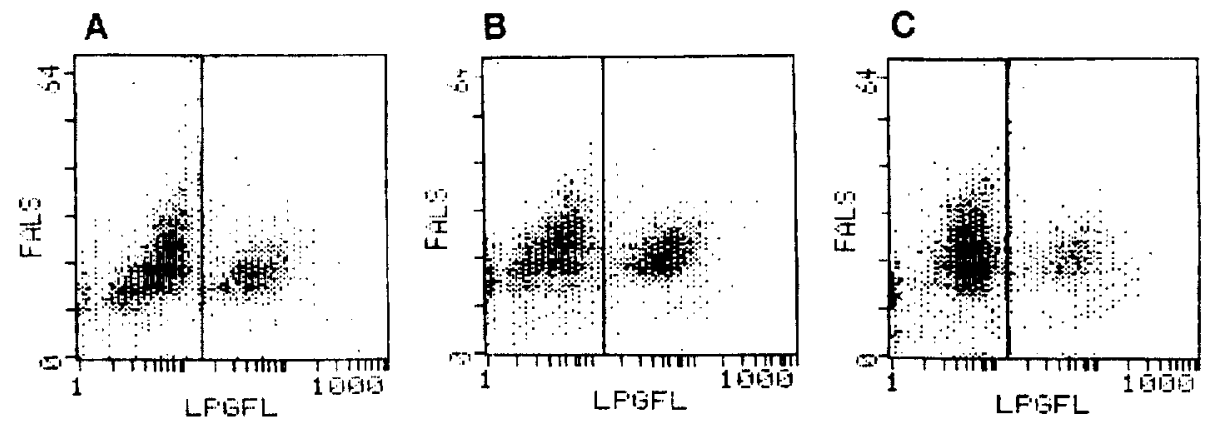

on manual counts, were 1) $23 \pm 1.5$ (flight) and $21 \pm$ $4.8 \%$ (ground) for mixed cells, 2) $19 \pm 1.5$ (flight) and $24 \pm 2 \%$ (ground) for band 1 cells, and 3 ) $15 \pm 1.4$ (flight) and $13 \pm 2.7 \%$ (ground) for band 2 cells.

Because cell samples were limiting, flow cytometry of PRL cells after flight could not be done. Flow cytometric histograms of PRL cells before flight indicated that they were fairly uniform in size and staining intensity (Fig. 1); this result is consistent with earlier studies (6).

\section{Extracellular and Intracellular PRL During and After Flight}

Immunoreactive PRL (iPRL) \pm hydrocortisone $(H C)$. Relative to ground control samples, all flight media and intracellular extracts contained significantly less iPRL; in every case, this flight difference disappeared in the postflight culture period (Fig. 2). The addition of $\mathrm{HC}$ to the culture medium accentuated these general pat-
Fig. 2. Release (extracelluar) and content (intracellular) of immunoreactive PRL (Prl) from mixed, band 1 , and band 2 cells without hydrocortisone during and after microgravity. Data are means \pm SE expressed relative to number of PRL cells seeded into vials; $n=3$ vials. Error bars not shown fit within symbol. ${ }^{* *} P<0.01{ }^{* * *} P<$ 0.001

\section{Extracellular}

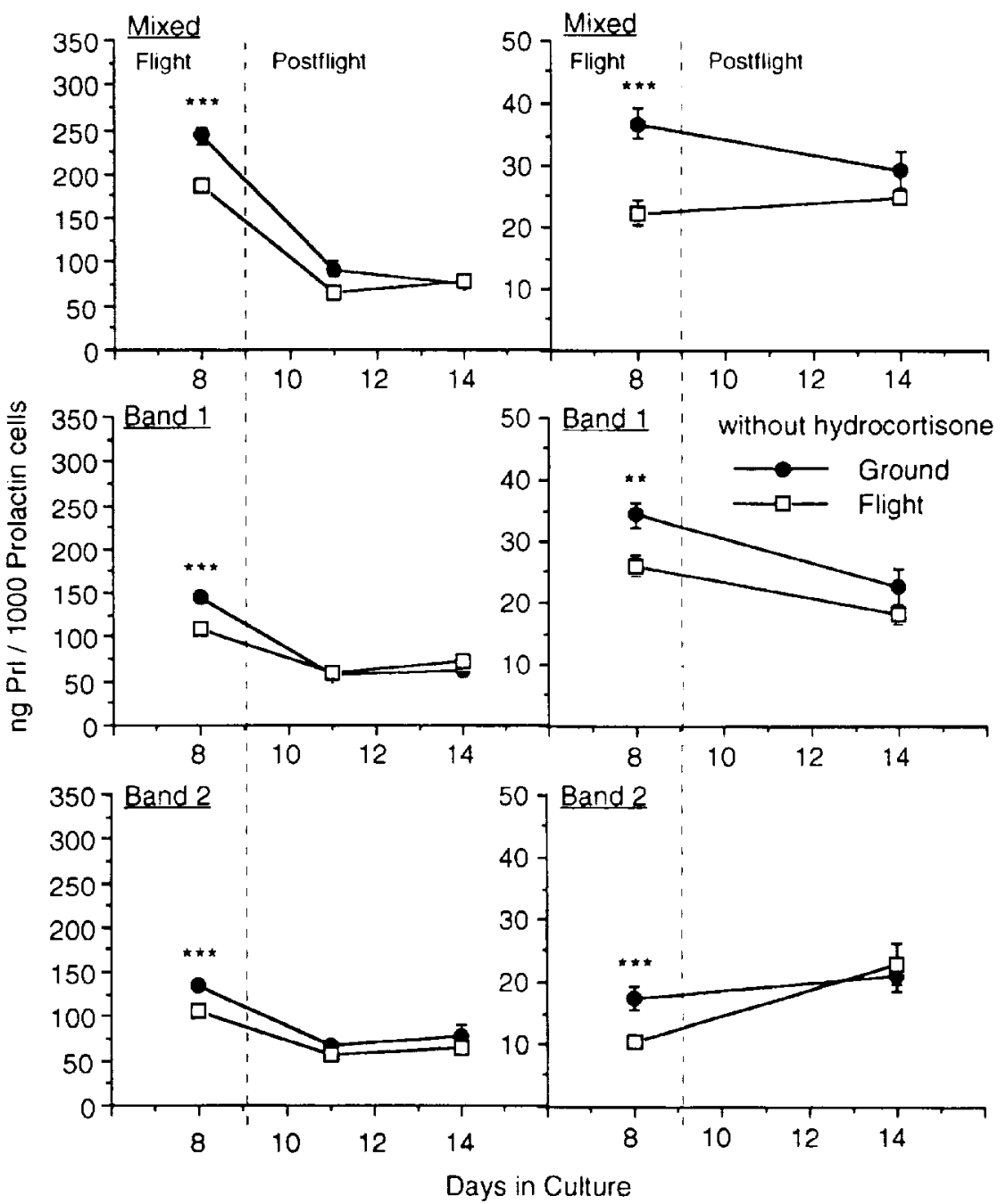


Extracellular $\quad$ Intracellular

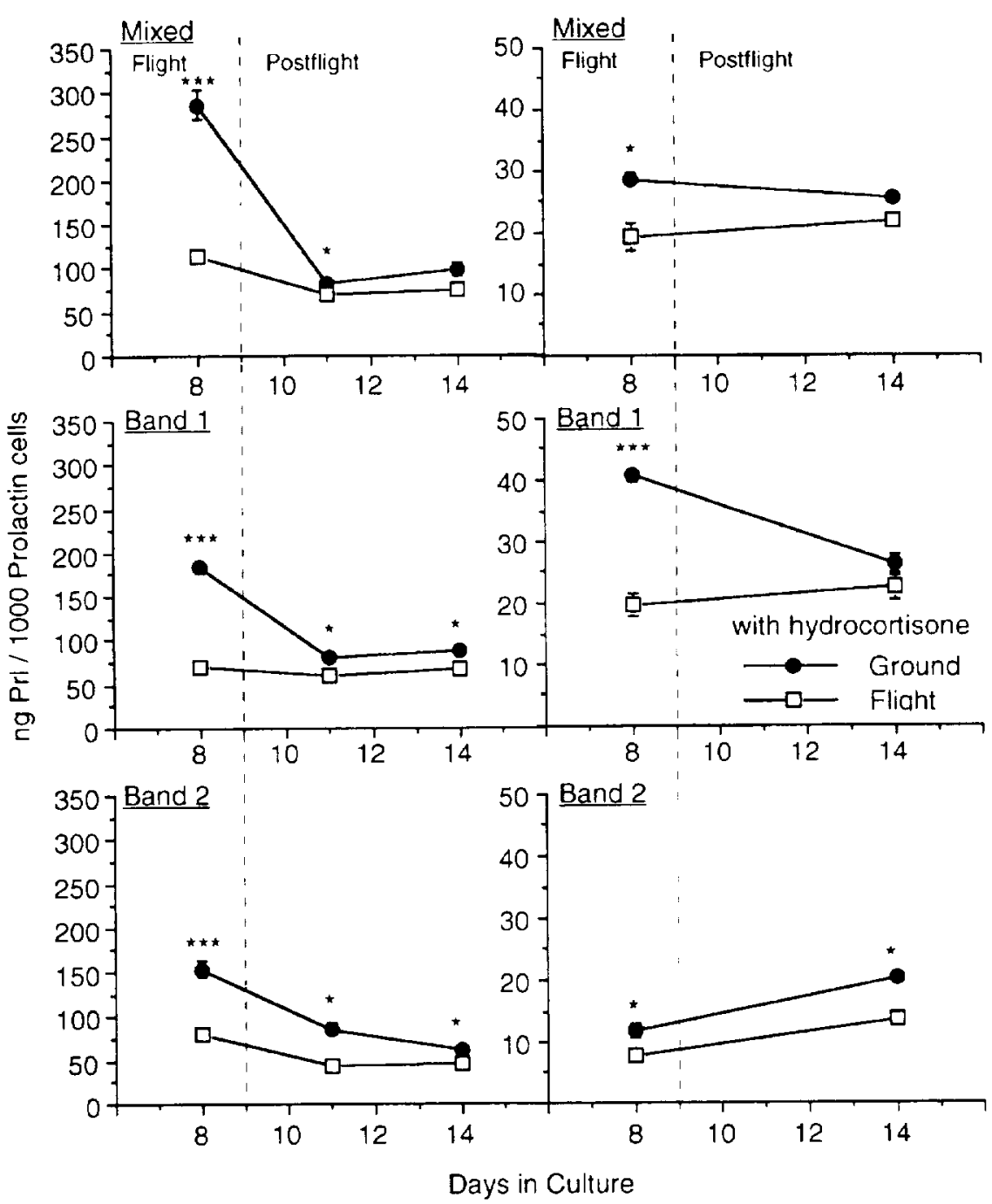

Fig. 3. Release and content of immunoreactive PRL from mixed, band 1 , and band 2 cells maintained in hydrocortisone-containing medium during and after microgravity. Data are means $\pm \mathrm{SE}$ expressed relative to number of PRL cells seeded into vials; $n=3$ vials. Error bars not shown fit within symbol. ${ }^{*} P<0.05$. ${ }^{* * *} P<0.001$. terns so that the flight differences often continued into the postflight period (Fig. 3).

Bioactive $P R L \pm H C: N B-2$ cell bioassay (NB-2 PRL) and mitogen bioassay ( $m$-PRL). Release of NB-2 PRL from cells in microgravity relative to ground control samples was variable and depended on both the cell sample and the presence of $\mathrm{HC}$ in the medium. HC significantly suppressed hormone release from the mixed and band 1 cells, whereas the output from band 2 cells in low gravity was significantly elevated in HC-free medium (cf. Figs. 4 and 5). Release of NB-2 PRL during the postflight period was usually less from the flight cells, independent of HC. A consistent reduction in the intracellular concentration of NB-2 PRL of HC-free cells indicated that the flight cells did not recover their intracellular contents during the 6-day postflight period; however, if $\mathrm{HC}$ was present in the culture medium, a full recovery was observed.

When these same culture media were evaluated by the $\mathrm{m}-\mathrm{PRL}$ assay, hormone release patterns were again different. The most significant responses were those in the postflight culture period in which flight cells often released significantly more $m$-PRL than did the corresponding ground control samples. However, in the presence of HC these changes disappeared (cf. Figs. 6 and 7).

HPLC analysis of released PRL. A majority of the iPRL molecules contained in 8-day culture media from flight and ground cells had apparent molecular weights ranging from 10,000 to 59,000 , with a predominant hormone peak at 29,000 (Fig. 8). There was significantly less $10,000-59,000$ iPRL contained in flight sample media from three of the six cell groups analyzed (Table 1). The addition of $\mathrm{HC}$ caused changes in the HPLC distribution profiles of iPRL released from mixed and band 1 cells. In the case of mixed cells, $\mathrm{HC}$ stimulated the release of high-molecular-weight iPRL from the flight cells threefold, whereas it was reduced by $\sim 60 \%$ in the absence of the steroid $(P<0.051)$. In the case of band 2 cells, the addition of $\mathrm{HC}$ reduced the release of 10,000-59,000 iPRL from ground cells to levels comparable with those from flight cells. The reason(s) for these changes is unknown. 
Fig. 4. Release and content of bioactive (NB-2 assay) PRL from mixed, band 1 , and band 2 cells without hydrocortisone during and after microgravity. Data are means $\pm S E$ expressed relative to number of PRL cells seeded into vials; $n=3$ vials. Error bars not shown fit within symbol. $* P<0.05$.
Extracellular

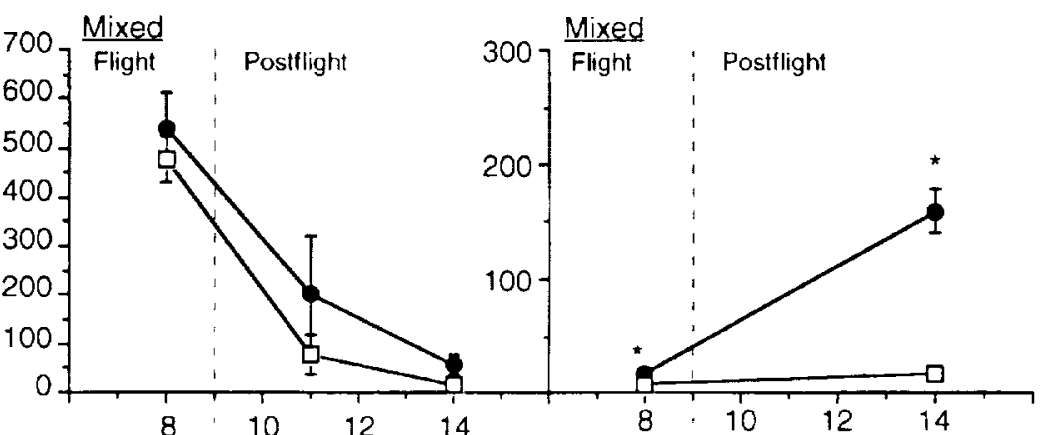

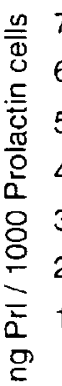

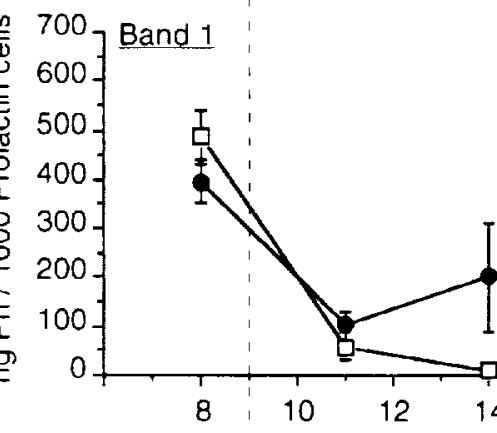

3007 Band 1

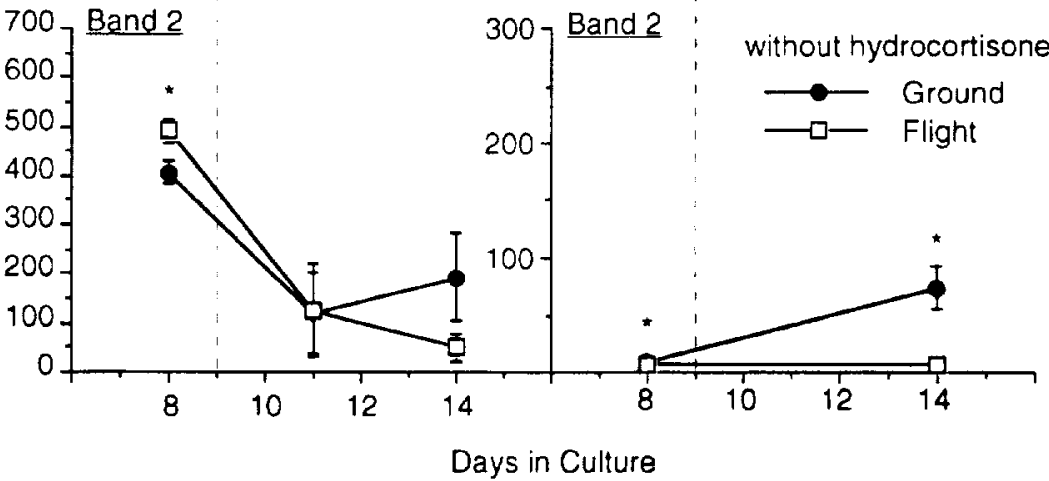

The total amount of iPRL recovered after HPLC of flight media was always less than that from the corresponding ground control groups. This result is entirely consistent with the finding that there were lower amounts of iPRL measured in the flight media before fractionation. Generally, the total amount of PRL recovered after HPLC of the flight and ground culture media agreed within $10 \%$ of what was measured in the sample before chromatography.

Substrate. Three vials containing mixed cells pretreated with Matrigel (a commercially available mixture of basement membrane macromolecules) were also exposed to low gravity. This treatment affected PRL release differently depending on the assay used. Release of iPRL from flight cells was $171 \pm 10 \mathrm{ng} / 1,000$ PRL cells, whereas that from ground control cells was $255 \pm 6 \mathrm{ng} / 1,000 \mathrm{PRL}$ cells $(P<0.01)$. Because a result of similar magnitude was found in iPRL released from cells attached to a non-Matrigel-coated surface (Fig. 2), we conclude that Matrigel had no additional effect on iPRL release in flight. Release of NB-2 PRL from mixed cells cultured on Matrigel was markedly different between flight and ground cells ( $622 \pm 222$ and $84 \pm 8$ ng $/ 1,000$ PRL cells, respectively; $P<0.05$ ). Comparison of these latter values with the release of NB-2 PRL on non-Matrigel-coated surfaces (Fig. 4) shows that this matrix material apparently had little effect on cell behavior in microgravity but severely inhibited release of NB-2 PRL at normal gravity. The reason(s) for this interesting result is unknown; we speculate that it may be related to the state of phosphorylation of PRL (see DISCUSSION). The release of $m$-PRL from cells on the Matrigel-coated surface was not different between flight and ground cells ( $250 \pm 40$ and $288 \pm 53 \mathrm{ng} / 1,000 \mathrm{PRL}$ cells, respectively). However, the total $m-P R L$ output was two times greater than that on the non-Matrigel surface.

Cell location. Flight consistently affected the release of PRL from cells residing in the dorsal vs. ventral regions of the gland. The direction and magnitude of the effect depended on the assay used. For example, iPRL release in microgravity was lower from both dorsal and ventral PRL cells by about the same extent (dorsal: $211 \pm 19$ and $371 \pm 24 \mathrm{ng}$ iPRL/1,000 PRL cells for flight and ground samples, respectively, $P<0.01$; ventral: $98 \pm 2$ and $162 \pm 10 \mathrm{ng}$ iPRL/1,000 PRL cells 
Extracellular

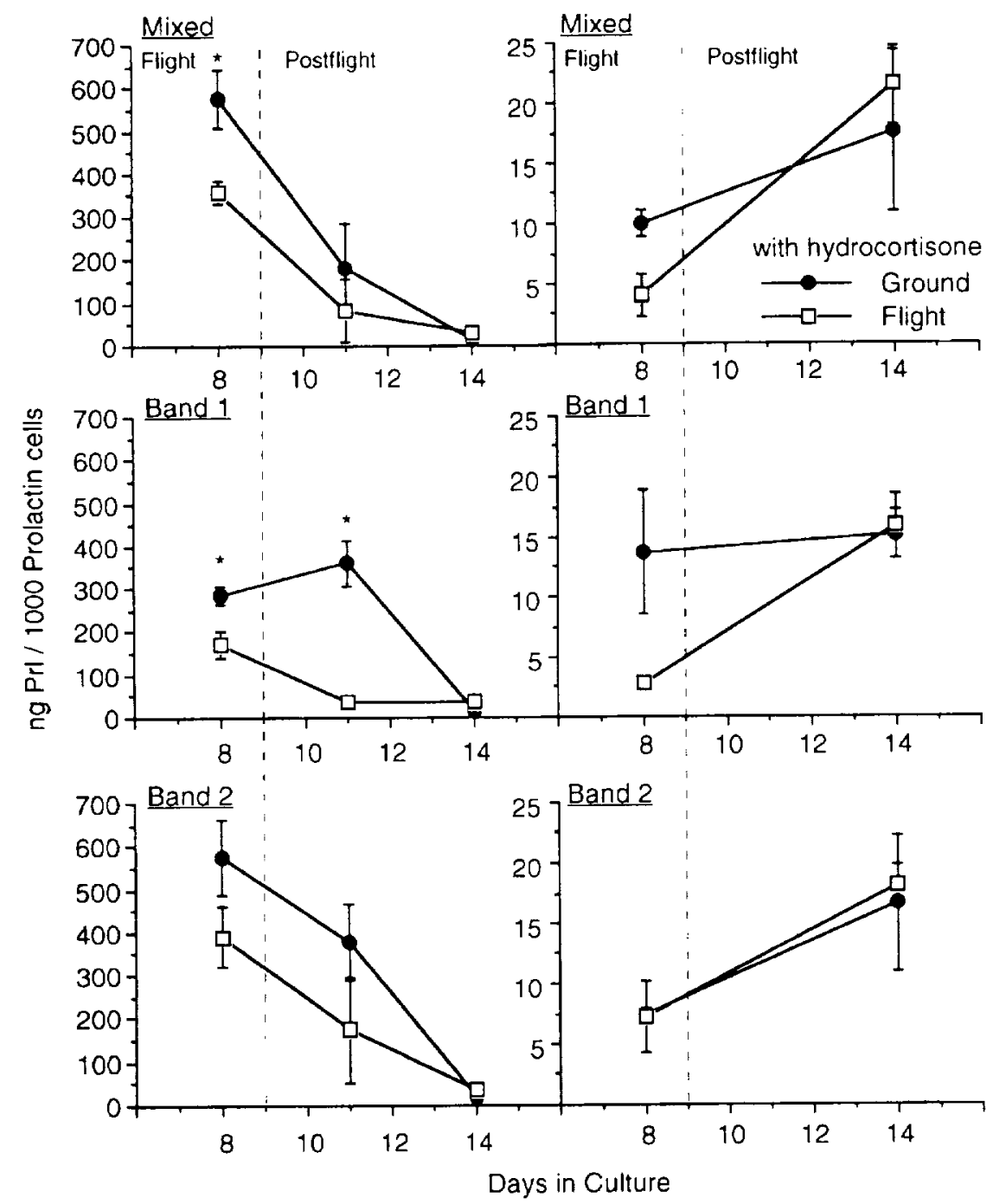

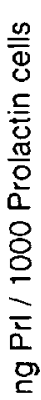

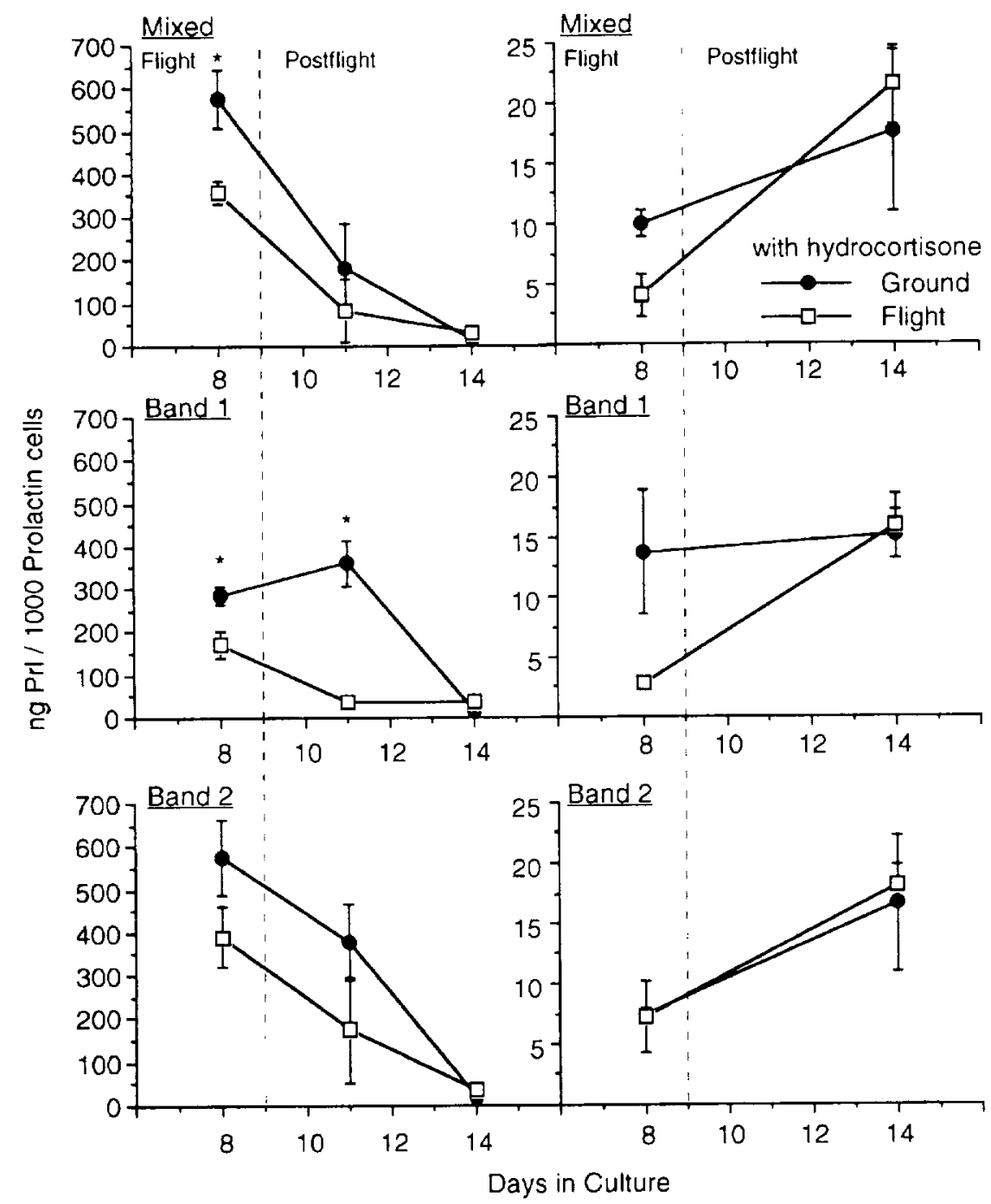

Intracellular
Fig. 5. Release and content of bioactive (NB-2 assay) PRL from mixed, band 1 , and band 2 cells maintained in hydrocortisone-containing medium during and after microgravity. Data are means $\pm \mathrm{SE}$ expressed relative to number of PRL cells seeded into vials; $n=3$ vials. Error bars not shown fit within symbol. ${ }^{*} P<0.05$. for flight and ground samples, respectively, $P<0.01$ ). By the NB-2 assay, release from the dorsal cells was significantly higher, whereas that from the ventral cells was not affected by microgravity (dorsal: $420 \pm 51$ and $293 \pm 44$ ng NB-2 PRL/1,000 PRL cells for flight and ground samples, respectively, $P<0.05$; ventral: $406 \pm$ 72 and $375 \pm 24$ ng NB-2 PRL $/ 1,000$ PRL cells for flight and ground samples, respectively, not significant). By the mitogen assay, PRL release from the dorsal and ventral cells in microgravity showed the most diverse response (dorsal: $69 \pm 25$ and $199 \pm 32 \mathrm{ng} \mathrm{m}-\mathrm{PRL} / 1,000$ PRL cells for flight and ground samples, respectively, $P<0.01$ ); ventral: $249 \pm 27$ and $130 \pm 10 \mathrm{ng}$ m-PRL 1,000 PRL cells for flight and ground samples, respectively, $P<0.01$ ).

\section{DISCUSSION}

Because PRL bears a close structural similarity to $\mathrm{GH}$, studies that are focused on one hormone often involve the other. In this way, comparisons of data involving the two hormones often help delineate the specificity of the hormonal effect. Studies that identify common features between GH and PRL are often those involving either intracellular processing or release of these hormones. Because the physiological responses resulting from the actions of either GH or PRL on the target cells are usually different, a major focus of this study was a determination of the effects of spaceflight on the activity of PRL molecules.

Observations appearing in the literature $\sim 30-40$ years ago implicated pituitary PRL in the control of immune tissue (1). Only in the last $10 \mathrm{yr}$ has that role been better defined. For example, 1) PRL appears to be an activator of T-cell function (21) and 2) PRL binds to well-characterized receptors on the surfaces of certain T cells, B cells, and macrophages (18). Because some of these same immune cell activities are compromised during and after spaceflight $(3,4,11,16)$, a purpose of the 1992 pituitary cell culture flight experiment (in addition to studying GH cells) (8) was to find out whether microgravity-induced changes also happened in PRL cell structure and function.

It has been recognized for many years that PRL and $\mathrm{GH}$ are separate molecules that are produced, stored, 
Fig. 6. Release and content of bioactive (mitogen assay) PRL from mixed, band 1 , and band 2 cells without hydrocortisone during and after microgravity. Data are means $\pm \mathrm{SE}$ expressed relative to number of PRL cells seeded into vials; $n=3$ vials. Error bars not shown fit within symbol. ${ }^{*} P<0.05$. ${ }^{* * *} P<0.001$.
Extracellular

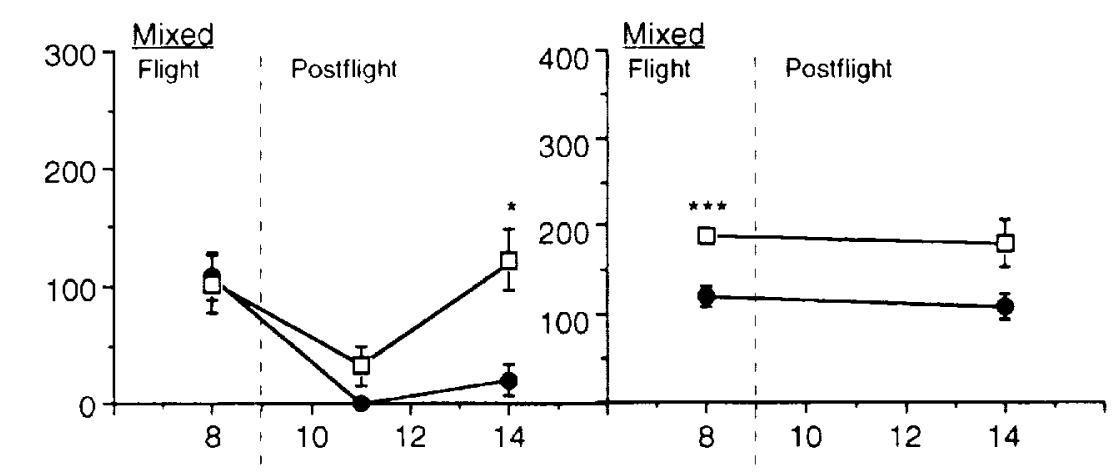

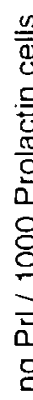

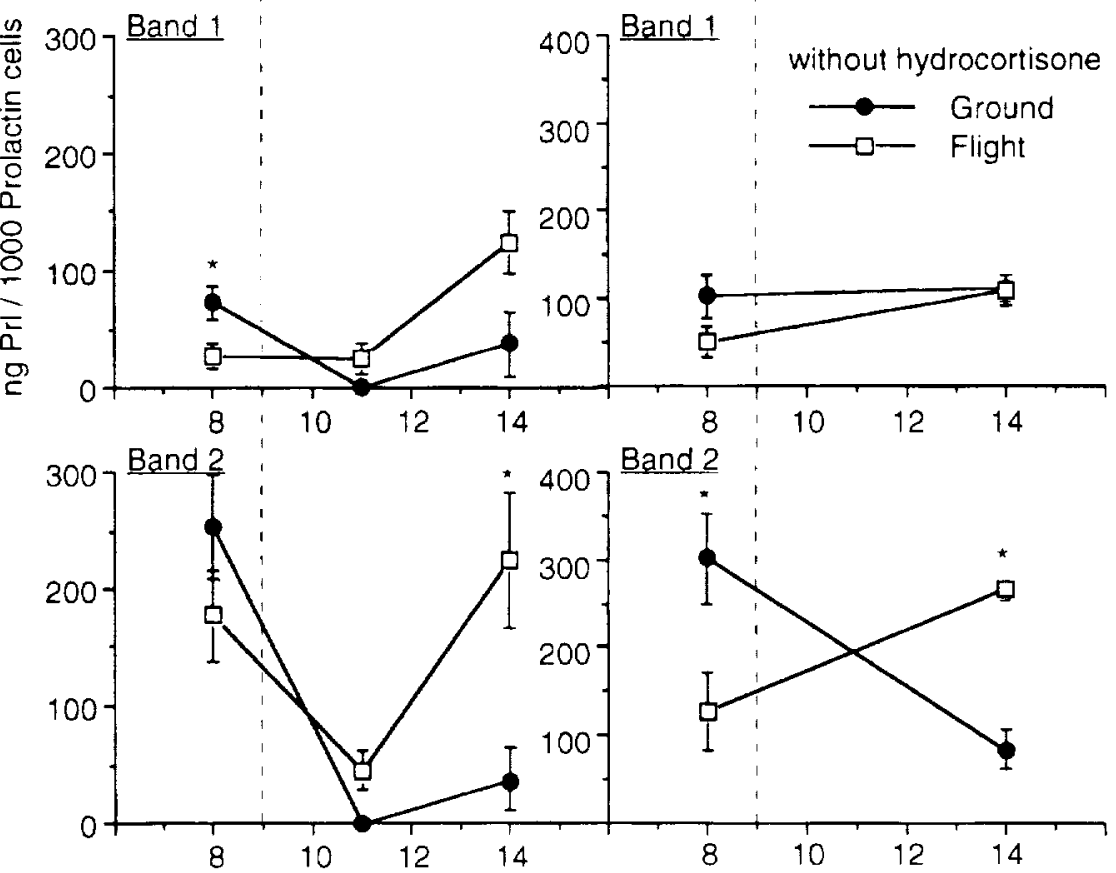

Days in Culture and released from separate cell types in the anterior pituitary. More recently, we have come to realize that PRL exists both within the gland and the bloodstream in a variety of different molecular forms, e.g., oligomeric, proteolytically cleaved, deamidated, phosphorylated, and glycosylated (20). The data obtained by gel-exclusion HPLC (Fig. 8) show that microgravity does not significantly change the apparent molecular weights of secreted PRL; therefore, it seems unlikely that aggregation or proteolytic cleavage of PRL is occurring as a result of spaceflight. On the other hand, the addition of $\mathrm{HC}$ to the culture medium tends to lower monomeric PRL during spaceflight. The reason(s) why $\mathrm{HC}$ negatively affects the release of low-molecularweight PRL from band 2 ground control cells is unknown.

In addition to molecular heterogeneity, the evidence for cellular heterogeneity in the PRL cell population is unequivocal. Not only are there PRL cell subpopulations within the gland [based on data indicating differences in PRL cell size, density, and laser light scatter (9,
15)], but newer observations describing a cell type that coreleases both PRL and GH (the mammosomatotroph) are now frequent. What is known about the morphology of the PRL cell after spaceflight?

Thapar et al. (23) recently evaluated PRL cell morphology of male rats after a 7-day spaceflight using techniques of histology, immunohistochemistry, morphometry, electron microscopy, and in situ hybridization. In their thorough study, they reported that 1) PRL cells appeared "evenly distributed throughout the gland, although there were some foci in which their accumulation was especially dense"; 2) PRL cells showed typical ultrastructure; 3) PRL cells had nuclear-to-cytoplasmic ratios that were unaffected by flight; and, finally, 4) PRL cells had signal intensities of PRL mRNA that were comparable in both groups. In addition to the cell culture study reported here, our laboratory also did morphological analyses on pituitary PRL cells from spaceflown male rats [3 flights (7)]. We failed to find differences in the number, size, staining intensity, and cytoplasmic area hormone occupancy between ground 
Extracellular $\quad$ Intracellular

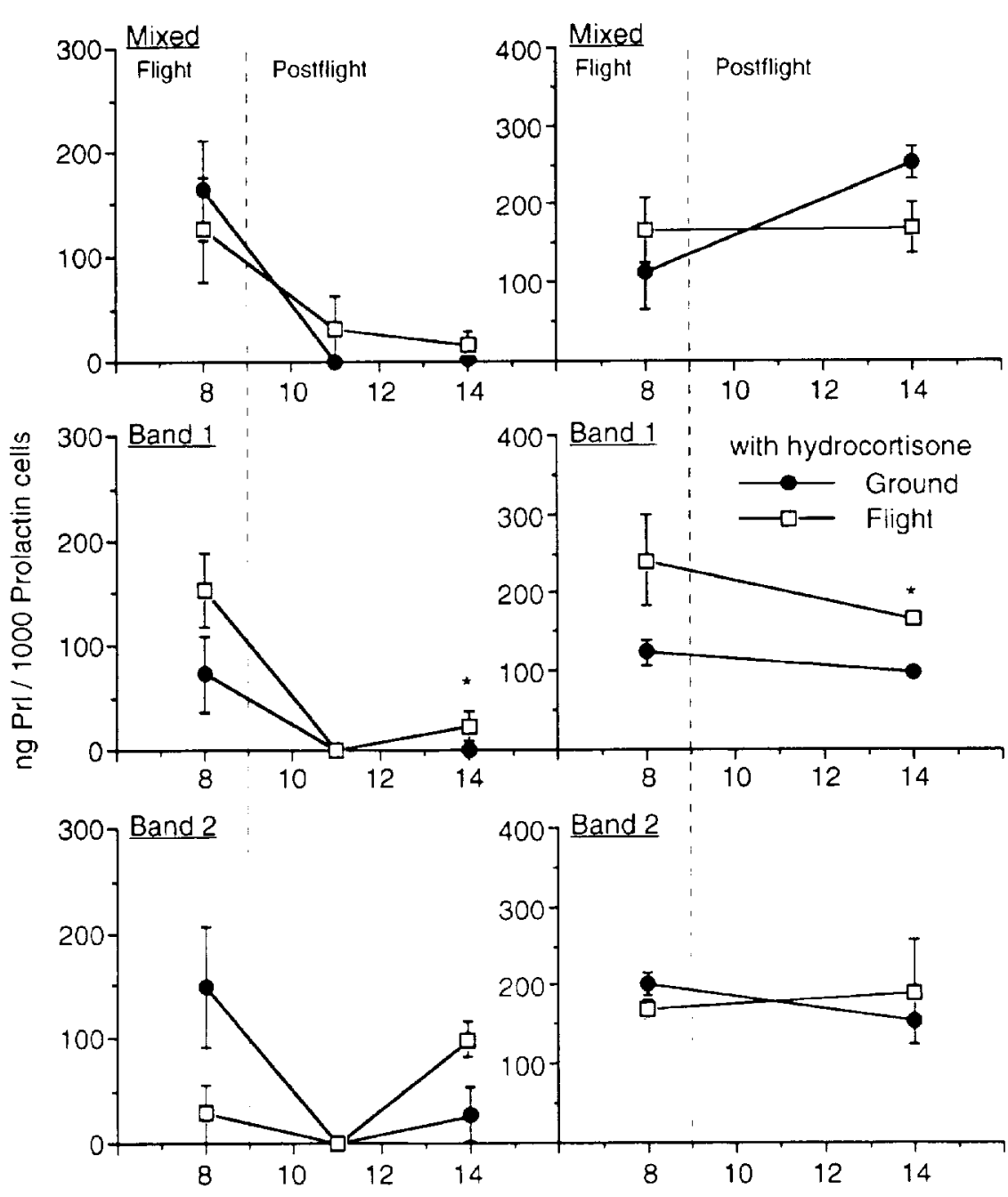

Fig. 7. Release and content of bioactive (mitogen assay) PRL from mixed, band 1 , and band 2 cells maintained in hydrocortisone-containing medium during and after microgravity. Data are means $\pm \mathrm{SE}$ expressed relative to number of PRL cells seeded into vials; $n=3$ vials. Error bars not shown fit within symbol. ${ }^{*} P<0.05$. and flight PRL cells. Therefore, the collective data of Thapar et al. (23) and our group (7) permit the inescapable conclusion that PRL cell morphology is not affected by short-term spaceflight.

How, then, can the functional differences in PRL cells that we previously reported from spaceflown rats (7), coupled with the numerous differences found in the present flight experiment (Figs. 2-8), be reconciled with these negative morphological data? We believe that posttranslational modifications of hormone molecules before their release could account, in part, for the apparent discrepancy. Such modifications are known to occur in PRL cells. For example, the recent studies of Walker (25) and Wang and Walker (26) show that PRL isoforms, molecules with the same molecular weight but different net charge, differ in their extent of phosphorylation. Most recently, this group showed that nonphosphorylated PRL promotes NB-2 cell proliferation, whereas the phosphorylated form inhibits this response. One-tenth the concentration of phosphorylated PRL neutralized the NB-2 cell growth-promoting effects of the rest of the PRL present. Other data from this same group demonstrate that the physiological status of the animal (e.g., different stages of the estrous cycle) reproducibly changes the ratio of phosphorylated to nonphosphorylated PRL molecules released from the pituitary (6).

A summary chart of the flight data from this cell culture experiment compared with ground control samples clearly shows that all flight media and intracellular extracts contain significantly less iPRL (Fig. 9). On the other hand, the results obtained from the two bioassays are often contradictory in that they do not agree between themselves and sometimes the PRL activity from fight group samples is even greater than from the ground samples. It is not difficult to imagine physiological situations in which the degree of phosphorylation of the PRL molecule might affect its bioactivity on lymphocytes differently because the lymphocytes we used were from either a tumor cell line or primary splenocytes. It would not be surprising that recognition of microgravity-induced phosphorylated PRL might be 

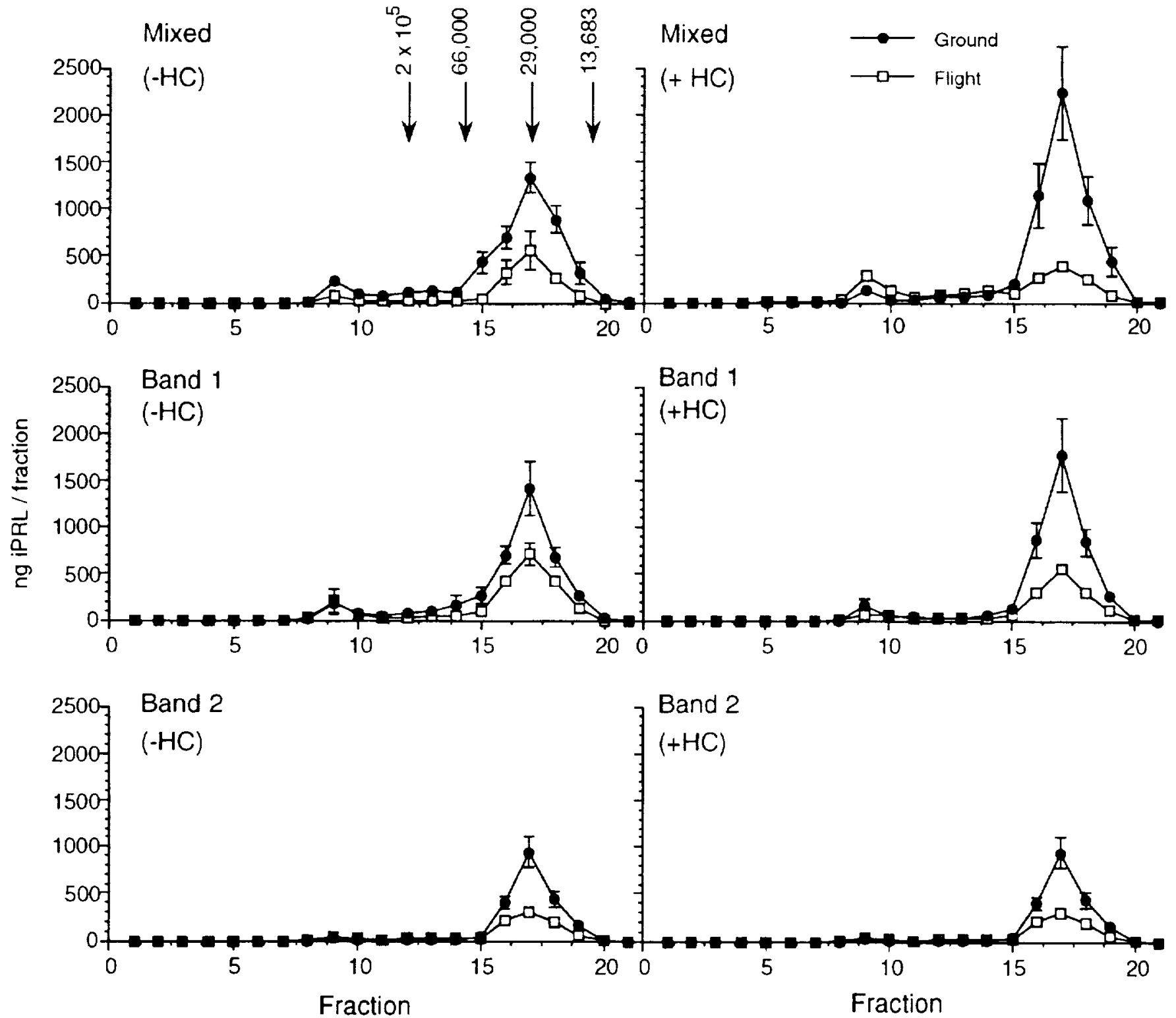

Fig. 8. Fractionation of culture media without $(-\mathrm{HC})$ and with hydrocortisone $(+\mathrm{HC})$ from spaceflown and ground control cells by gel-exclusion high-performance liquid chromatography. iPRL, immunoreactive PRL. Elution positions of standard molecular-weight markers (blue dextran, 2,000,000; $\beta$-amylase, 200,000; bovine serum albumin, 66,000; carbonic anhydrase, 29,000; and ribonuclease, 13,683) are shown in upper left panel.

recognized differently in the two assays. In support of this argument, we refer to two recent studies from our laboratory $(12,13)$ that show that reciprocal activities between these two assays correlate with the physiological state of the animal. Thus PRL released 1) from cells contained in different regions of the pituitary glands of female rats that are in different stages of the estrous cycle (13) and 2) from cells of rats bearing carcinogeninduced mammary tumors (12) both show differential activities in the two bioassays. It is relevant to point out that we were able to identify two different types of PRL cells (based on their laser light scatter) in the glands of donors at different stages of the estrous cycle; these changed in frequency within the dorsal and ventral regions of the gland at specific stages. We also found that the ratios of PRL activities released from these cells, measured by immunoassay and bioassay, also correlated with cycle stage and region (13). In this regard, it is especially interesting that our new data also show that the region from which the PRL cells were prepared make a difference both in terms of their sensitivity to changes in gravity levels as well as in the activity of PRL molecules released from them. Because the only significant effect of flight on regional GH release was from dorsal cells (8), it is clear that regional changes in PRL cells reflect more sensitivity and plasticity to their gravity environment. The reason(s) for these differences is unknown; however, it offers insights into experimental designs for future flights.

Complex biological mechanisms that assure proper function of hormone-producing cells in a neuroendocrine system may be remarkably similar to those controlling a properly functioning immune system. In fact, common molecular mechanisms of communication 
Table 1. Effect of microgravity on release of iPRL forms based on size distribution patterns after fractionation by gel exclusion HPLC

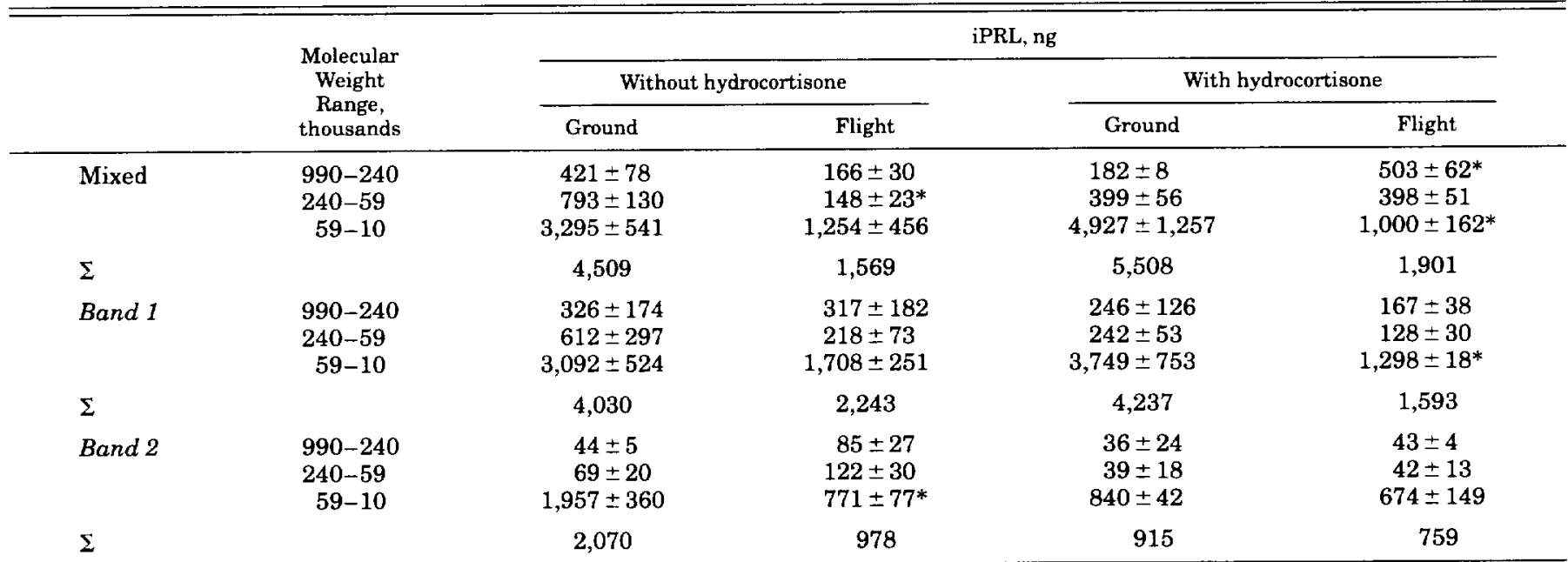

Values are immunoreactive prolactin (iPRL) in combined high-performance liquid chromatography (HPLC) fractions \pm SE; $n=3$ cell groups. ${ }^{*} P \leq 0.05$ compared with ground cells.

between these two systems via shared signal molecules (including peptide hormones, peptide neurotransmitters, and cytokines) have been identified by Blalock and Weigent $(2)$ as the means by which the integration of organ system function is realized; in fact, these ideas "could change our understanding of physiology and thus influence medical practice." Common molecular mechanisms of communication must certainly take place as cells sense and respond to changes in their environments. Because cells accomplish their communications in a fluid environment and because the behavior of fluids is very different in microgravity, it is perhaps not too surprising that pituitary cell physiol- ogy is affected by spaceflight. Our experimental data establish that hormone-producing pituitary cells sense gravity and respond by changing the amounts and activities of product that are contained in, and released from, the cell. At this point, we do not understand the biochemical mechanism(s) by which these changes take place, but our data establish that they can be manipulated by changing the cell culture system. An understanding of the equally complex but poorly understood biophysical mechanisms involved in the cellular adaptation to microgravity will also be required to establish countermeasures to physiological changes encountered during manned spaceflight. Our studies, together with

\begin{tabular}{|c|c|c|c|c|c|c|c|c|}
\hline \multicolumn{5}{|c|}{$\begin{array}{l}\text { RELEASED PRL } \\
\text { (No Hydrocortisone) }\end{array}$} & \multicolumn{4}{|c|}{$\begin{array}{l}\text { INTRACELLULAR PRL } \\
\text { (No Hydrocortisone) }\end{array}$} \\
\hline \multirow[b]{2}{*}{ Assay } & \multirow[b]{2}{*}{ Cell } & \multirow[b]{2}{*}{ Flight } & \multicolumn{2}{|c|}{$\begin{array}{l}\text { Postflight } \\
\text { Culture }\end{array}$} & \multirow[b]{2}{*}{ Assay } & \multirow[b]{2}{*}{ Cell } & \multirow[b]{2}{*}{ Flight } & \multirow{2}{*}{$\begin{array}{l}\text { Postflight } \\
\text { Culture } \\
6 \text { days }\end{array}$} \\
\hline & & & 3 days & 6 days & & & & \\
\hline \multirow[t]{3}{*}{$\mathrm{Nb}-2$} & Mixed & & & & $\mathrm{Nb}-2$ & Mixed & & \\
\hline & Band 1 & & & & & Band 1 & & \\
\hline & Band 2 & & & & & Band 2 & & \\
\hline \multirow[t]{3}{*}{ Mitogen } & Mixed & & & & Mitogen & Mixed & & \\
\hline & Band 1 & & & & & Band 1 & & \\
\hline & Band 2 & & & & & Band 2 & & \\
\hline \multirow[t]{3}{*}{ EIA } & Mixed & & & & EIA & Mixed & & \\
\hline & Band 1 & & & & & Band 1 & & \\
\hline & Band 2 & & & & & Band 2 & & \\
\hline \multicolumn{5}{|c|}{$\begin{array}{c}\text { RELEASED PRL } \\
\text { (With Hydrocortisone) }\end{array}$} & \multicolumn{4}{|c|}{$\begin{array}{l}\text { INTRACELLULAR PRL } \\
\text { (With Hydrocortisone) }\end{array}$} \\
\hline \multirow[t]{3}{*}{$\mathrm{Nb}-2$} & Mixed & & & & $\mathrm{Nb}-2$ & \begin{tabular}{|l|} 
Mixed \\
\end{tabular} & & \\
\hline & Band 1 & & & & & Band 1 & & \\
\hline & Band 2 & & & & & Band 2 & & \\
\hline \multirow[t]{3}{*}{ Mitogen } & Mixed & & & & Mitogen & Mixed & & \\
\hline & Band 1 & & & & & Band 1 & & \\
\hline & Band 2 & & & & & Band 2 & & \\
\hline \multirow[t]{3}{*}{ EIA } & Mixed & & & & $E \mid A$ & Mixed & & \\
\hline & Band 1 & & & & & Band 1 & & \\
\hline & Band 2 & & & & & Band 2 & & \\
\hline
\end{tabular}

Fig. 9. Summary of flight effects on extracellular and intracellular PRL as a function of cell sample, hormone assay, hydrocortisone, and postflight incubation. EIA, enzyme immunoassay. Responses between flight and ground are represented as not significant (open boxes); flight significantly greater than ground ( $P<0.05$; hatched boxes); flight significantly less than ground $(P<$ 0.05 ; solid boxes). 
a growing number of others, thus serve as a precursor to follow on investigations that can be done on a routine basis when the new Space Station is operational.

The authors thank E. J. Grossman for help in collecting tissue samples.

This study was supported in part by National Aeronautics and Space Administration Grant NCC 2-370 and by National Cancer Institute Grant CA-23248 to W. C. Hymer.

This work was presented in part at the meeting of the American Society of Gravitational and Space Biology in Washington, DC, in 1993.

Address for reprint requests: W. C. Hymer, 006 Althouse Laboratory, The Pennsylvania State Univ., University Park, PA 16802.

Received 18 January 1995; accepted in final form 28 September 1995

\section{REFERENCES}

1. Berczi, I., and E. Nagy. Pituitary function and immunology In: Pituitary Function and Immunology, edited by I. Berczi. Boca Raton, FL: CRC, 1986, p. 168-183.

2. Blalock, J. E., and D. A. Weigent. Pituitary control of immune cells. Immunol. Today 15: 39, 1994.

3. Chapes, S. K., D. R. Morrison, J. A. Guikema, M. L. Lewis, and $B . S$. Spooner. Cytokine secretion by immune cells in space. J. Leukocyte Biol. 52: 104-110, 1992.

4. Cogoli, A. Changes observed in lymphocyte behavior during gravitational unloading. ASGSB Bull. 4: 107-115, 1991

5. Hatfield, J. M., and W. C. Hymer. Flow cytometric analysis and sorting of live female rat anterior pituitary cell types by forward angle and perpendicular light scatter: effect of $17 \beta$-estradiol. Endocrinology 119: 2683-2694, 1986.

6. Ho, T. W. C., F. S. Leong, C. H. Olaso, and A. M. Walker. Secretion of specific nonphosphorylated and phosphorylated rat PRL isoforms at different stages of the estrous cycle. Neuroendocrinology 58: 160-165, 1993.

7. Hymer, W. C., R. Grindeland, I. Krasnov, I. Victorov, K. Motter, P. Mukherjee, K. Shellenberger, and M. Vasques. Effects of spaceflight on rat pituitary cell function. J. Appl. Physiol. 73, Suppl.: 151S-157S, 1992.

8. Hymer, W. C., R. E. Grindeland, T. Salada, P. Nye, E. Grossman, and P. Lane. Experimental modification of rat pituitary growth hormone cell function during and after spaceflight. J. Appl. Physiol. 80: 955-970, 1996.

9. Hymer, W. C., and J. Hatfield. Purification of cells from the anterior pituitary. In: Methods in Enzymology, edited by S. P. Colowick and N. O. Kaplan. San Diego, CA: Academic, 1983, vol. 103 , pt. H, p. 257-287.

10. Lawson, D. M., D. J. Haisenleder, R. R. Gala, and J. A. Moy. The occurrence of pituitary prolactin depletion-transformation in lactating rats: dependence on strain of rats, homogenization conditions and method of assay. J. Endocrinol. 113: 71-80, 1987.
11. Limouse, M., S. Manie, I. Konstantinova, B. Ferrua, and L. Schaffar. Inhibition of phorbol ester-induced cell activation in microgravity. Exp. Cell Res. 197: 82-86, 1991.

12. Mukherjee, P., U. Hauser, A. M. Mastro, and W. C. Hymer. Prolactin-immune interactions in carcinogen-induced rat mammary tumors. Endocr. Res. 20: 395-412, 1994.

13. Mukherjee, $\mathbf{P}$, and W. C. Hymer. Heterogeneity of rat pituitary prolactin cells: relationships between location, hormone assay, and estrous cycle stage. Prog. Neuroendocrinimmunol. 5: $108-119,1992$.

14. Mukherjee, P., A. Mastro, and W. C. Hymer. Prolactin induction of interleukin-2 receptors on rat splenocytes. Endocrinology 126: 88-94, 1990.

15. Mukherjee, P., T. Salada, and W. C. Hymer. Function of prolactin cells in the individual rat pituitary gland is location dependent. Mol. Cell. Endocrinol. 76: 35-44, 1991.

16. Nash, P. V., and A. M. Mastro. Variable lymphocyte responses in rats after space flight. Exp. Cell Res. 202: 125-131, 1992.

17. Nicoll, C. S. Handbook of Physiology. Endocrinology. The Pituitary Gland and Its Neuroendocrine Control. Washington, DC: Am. Physiol. Soc., 1974, sect. 7, vol. IV, pt. 2, p. 253.

18. Russell, D. H., L. Matrisian, R. Kibler, D. F. Larson, B. Poulos, and B. E. Magum. Prolactin receptors on human T and $B$ lymphocytes: antagonism of prolactin binding by cyclosporine. J. Immunol. 134: 3027-3031, 1985.

19. Signorella, A, and W. C. Hymer. Development of an enzymelinked immunoabsorbent assay for rat prolactin. Anal. Biochem. 136: 372-381, 1984

20. Sinha, Y. N. Prolactin variants. Trends Endocrinol. Metab. 3 100-106, 1992.

21. Spangelo, B. L., N. R. Hall, and A. L. Goldstein. Evidence that prolactin is an immunomodulatory hormone. In: Prolactin. Basic and Clinical Correlates, edited by R. M. MacLeod, M. O. Thorner, and U. Scapagnini. Padova, Italy: Liviana, 1985, p. $345-349$.

22. Tanaka, T., R. P. C. Shiu, P. W. Gout, C. T. Beer, R. L. Noble, and $H$. G. Friesen. A new sensitive and specific bioassay for lactogenic hormones: measurement of prolactin and growth hormone in human serum. J. Clin. Endocrinol. Metab. 51: 1058-1063, 1980.

23. Thapar, K., K. Kovacs, E. Horvath, L. Stefaneanu, E. Chambers, and A. J. Mortimer. Effects of spaceflight on morphology of the rat adenohypophysis. J. Appl. Physiol. 77: 1411-1420, 1994.

24. Viselli, S. M., E. M. Stanek, P. Mukherjee, W. C. Hymer, and A. M. Mastro. Prolactin-induced mitogenesis of lymphocytes from ovariectomized rats. Endocrinology 129: 983-990, 1991.

25. Walker, A. M. Phosphorylated and nonphosphorylated prolactin isoforms. Trends Endocrinol. Metab. 5: 195-200, 1994

26. Wang, Y., and A. M. Walker. Dephosphorylation of standard prolactin produces a more biologically active molecule: evidence for antagonism between nonphosphorylated and phosphorylated prolactin in the stimulation of $\mathrm{Nb}_{2}$ cell proliferation. Endocrinology 133: 2156-2160, 1993. 